\title{
АНАЛИЗ СТРАТЕГИИ АО «НК «КАЗМУНАЙГАЗ»
}

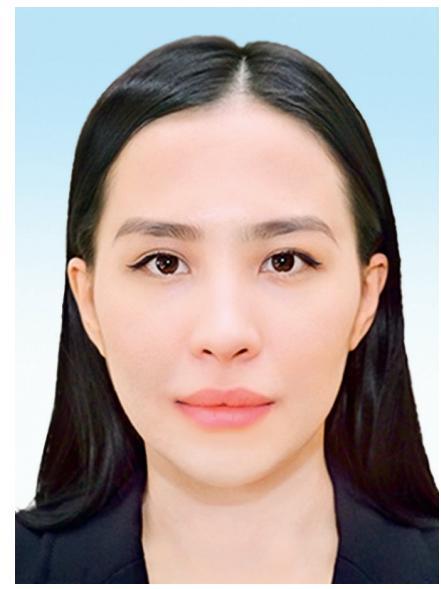

T.P. HA3APOBA, магистрант МВА Высшей школы бизнеса университета международного бизнеса, https://orcid.org/0000-00028634-989X

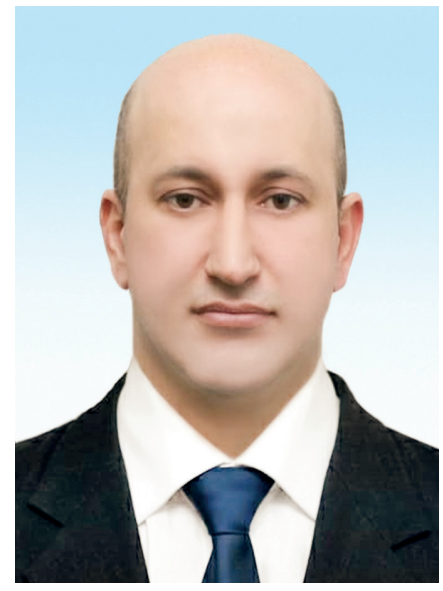

Ж.Д. ОСМАНОВ

кандидат экономических наук, https://orcid.org/0000-00025225-0365

УНИВЕРСИТЕТ МЕЖДУНАРОДНОГО БИЗНЕСА, Республика Казахстан, 050010, г. Алматы, пр. Абая, 8А

Нефртегазовая отрасль ежегодно сталкивается со многими вызовами внешней и внутренней среды. Несомненно, чтобы преодолеть все трудности и вызовы нефртегазовые компании нуждаются в разработке эфффективной стратегии развития и в ее успешной реализации.

В рамках этой научной статьи приводятся особенности фрункционирования компании $A О$ «НК «КазМунайГаз» в условиях неопределенности развития мирового нефтяного рынка. На основании опубликованных данных ежегодных отчетностей проведен анализ ключевых производственно-хозяйственных показателей $A O$ «НК «КазМунайГаз» за 2014-2020 годы. По результатам анализа, было выявлено, какие ключевые показатели отклоняются от стратегических целей компании. Далее, при помощи инструмента стратегического анализа SWOT проводится определение сильных и слабых сторон, а также угроз и возможностей компании. В результате комплексного анализа выводятся рекомендации по совершенствованию стратегии компании.

КЛЮчЕВЫЕ СЛОВА: стратегия, стратегический менеджмент, вертикально-интегрированная компания, нефть, нефртегазовая компания, SWOT анализ.

\footnotetext{
* Адрес для переписки. E-mail: zhasym@mail.ru
} 


\section{«ҚАЗМҰНАЙГАЗ» ҰК》 АҚ СТРАТЕГИЯСЫН ТАЛДАУ}

T.P. HАЗАРОВА, Халықаралық Бизнес Университеті Жоғары бизнес мектебінің МВА магистранты, https://orcid.org/0000-0002-8634-989X

ж.Д. ОСМАНОВ*, экономика ғылымдарының кандидаты, https://orcid.org/0000-0002-5225-0365

ХАЛЫҚАРАЛЫҚ БИЗНЕС УНИВЕРСИТЕТІ,

Қазақстан Республикасы,050010, Алматы қаласы, Абай даңғылы, 8А

Мұнай-газ саласы жыл сайын сыртқы және ішкі ортаның көптеген сын-тегеуріндерімен бетпе-бет келеді. Барлық қиындықтар мен сын-қатерлерді еңсеру үшін мұнайгаз компаниялары тиімді даму стратегиясын әзірлеуді және оны табысты іске асыруды қажет ететіні сөзсіз.

Осы ғылыми мақаланың шеңберінде "ҚазМұнайГаз "ҰК" АҚ компаниясының әлемдік мұнай нарығының дамуының белгісіздігі жағдайында жұмыс істеу ерекшеліктері келтіріледі. Жыл сайынғы есептіліктердің жарияланған деректері негізінде "ҚазМұнайГаз "ҰК" АҚ-ның 2014-2020 жылдардағы негізгі өндірістік-шаруашылық көрсеткіштеріне талдау жүргізілді. Талдау нәтижелері бойынша Компанияның стратегиялық мақсаттарынан қандай негізгі көрсеткіштер ауытқып кететіні анықталды. Әрі қарай, SWOT стратегиялық талдау құралының көмегімен күшті және әлсіз жақтар, сондай-ақ компанияның қауіптері мен мүмкіндіктері анықталады. Кешенді талдау нәтижесінде компанияның стратегиясын жетілдіру бойынша ұсыныстар шығарылады.

ТҮЙІн СөзДЕР: стратегия, стратегиялық менеджмент, тігінен интеграцияланған компания, мұнай, мұнай-газ компаниясы, SWOT талдау.

\section{ANALYSIS OF THE STRATEGY OF NC KAZMUNAYGAS JSC}

T.R. NAZAROVA, MBA student at GSB, University of International Business, https://orcid.org/00000002-8634-989X

Z.D. OSMANOV*, Candidate of Sciences in Economics, https://orcid.org/0000-0002-5225-0365

UNIVERSITY OF INTERNATIONAL BUSINESS

8A, Abay ave. Almaty, 050010, Republic of Kazakhstan

The oil and gas industry annually faces many challenges of the external and internal environment. Undoubtedly, in order to overcome all the difficulties and challenges, oil and gas companies need to develop an effective strategy and successfully implement it.

Within the framework of this scientific article, the features of the functioning of NC KazMunayGas JSC in the conditions of uncertainty about the development of the world oil market are presented. Based on the published data of the annual reports, an analysis of the key production and economic indicators of NC KazMunayGas JSC for 2014-2020 was carried out. According to the results of the analysis, it was revealed which key indicators deviate from the company's strategic goals. Further, the SWOT strategic analysis tool is used to determine the strengths and weaknesses, as well as threats and opportunities of the company. As a result of a comprehensive analysis, recommendations for improving the company's strategy are derived.

KEY WORDS: strategy, strategic management, vertically integrated company, oil, oil and gas company, SWOT analysis.

$\mathrm{H}$ ефтегазовая отрасль ежегодно сталкивается со многими вызовами внешней и внутренней среды: волатильность мировых цен на нефть, дисбаланс в соотношении спроса и предложения на нефтяном рынке, естественное падение добычи, рост затрат и снижение доходов и другие. В 2020 году данный 
список вызовов пополнился еще одним - пандемия коронавируса. Ввиду вышеуказанных рыночно-экономических изменений, нефтегазовым компаниям необходимо разрабатывать эффективные стратегии и планирование, которые могут позволить предприятию в ближайшей и долгосрочной перспективе успешно развиваться в конкурентной среде, т.е. в обстановке, подверженной радикальным, быстрым и зачастую непредсказуемым изменениям [1, с. 140].

Целью исследования - анализ соответствия реализации стратегии АО «НК «КазМунайГаз» до 2025 года ее основным стратегическим целям; провести изучение и анализ стратегии $\mathrm{AO}$ «НК «КазМунайГаз» на предмет соответствия внешним вызовам.

Задачи: изучить основные положения стратегии АО «НК «КазМунайГаз» до 2025 года; проанализировать динамику ключевых показателей производственно-финансовой деятельности АО «НК «КазМунайГаз»; доказать соответствие или несоответствие мер реализации стратегии ее ключевым целям; выявить через SWOT-анализ взаимосвязь между изменениями во внешней и внутренней средах; сформировать выводы, на основе которых выдвинуть рекомендации.

Согласно А.А. Томпсон-мл. и А.Дж. Стрикленд III [2, с. 49-50], стратегический менеджмент - это непрерывный и бесконечный процесс, а не некое одноразовое мероприятие, выполнив которое, можно спокойно заниматься другими делами. Менеджеры обязаны ежедневно анализировать происходящие события и решать, требуют они соответствующей корректировки стратегии или нет. Менеджерам необходимо отслеживать прогресс в деятельности организации, выявлять проблемы, определять тенденции рынка и потребительских предпочтений, при необходимости корректировать действия.

Центральным звеном стратегического управления является стратегический выбор, основанный на сопоставлении собственного ресурсного потенциала предприятия с возможностями и угрозами внешней среды [3, с. 120].

Реализация стратегических решений предусматривает оценку хода внедрения общей стратегии, возможность и целесообразность дальнейшего исследования заданной стратегии, принципиальную достижимость посредством данной стратегии основных стратегических целей и миссии организации [4, с. 149].

В то же время, следует учитывать, что реализация стратегии является критическим процессом, так как именно он в случае успешного осуществления приводит предприятие к достижению поставленных целей [5, с. 11].

Майкл Ковени писал, что финансовые результаты организации являются конечным итогом удачной или неудачной реализации ее стратегии [6, с. 24].

Также не нужно забывать, что стратегический менеджмент дает возможность отказаться от неперспективных направлений развития, не дожидаясь неудовлетворительного результата, не пытаться угнаться за конкурентами, а самому первым занять перспективную нишу, уметь увидеть в наступающих переменах не проблемы, а новые возможности [7, с. 6].

Методы исследования. Изучениние ситуации, документальные исследования, сравнительный анализ. 
Гипотеза. Соответствуют ли реализация Стратегии АО «НК «КазМунайГаз» до 2025 года ее основным стратегическим целям?

Базой для сбора данных являются платформа научных публикаций Google Scholar, научно-учебные пособия, а также отчеты компании.

$\mathrm{AO}$ «НК «КазМунайГаз» (КМГ) является ведущей вертикально - интегрированной нефтегазовой компанией Казахстана. КМГ управляет активами по всему производственному циклу от разведки и добычи углеводородов до транспортировки, переработки и предоставления сервисных услуг» [8].

Согласно Стратегии КМГ, до 2025 года основными целями являются:

- повышение уровня запасов и объемов добычи;

- укрепление финансовой устойчивости и создание стоимости;

- гарантия возвратности инвестиций.

В рамках установленных стратегических целей компания предпринимает определенные меры для реализации стратегии по основным направлениям производственного цикла. А именно:

1) По разведке и добыче:

- развитие ресурсной базы для обеспечения устойчивого развития в среднесрочной (до 2025 г.) и долгосрочной (после 2025 г.) перспективе;

- повышение операционной эффективности добычи;

- обеспечение прироста добычи углеводородов в большей степени за счет органического роста.

2) По транспортировке нефти:

- повышение эффективности транспортировки через нефтепроводы;

- увеличение загрузки мощностей морского нефтетранспорта;

- повышение объемов транспортировки нефти на внутреннем рынке.

3) По транспортировке газа и маркетингу газа:

- увеличение рентабельности бизнес-направления транспортировки газа;

- применение сжиженного углеводородного газа для газификации небольших населенных пунктов;

- развитие транзитного транспортного потенциала и усиление в направлении КНР экспортного потенциала.

Изучив общую информацию о компании, а также ее среднесрочные стратегические цели и меры реализации стратегии, проведем изучение изменений ключевых производственно-финансовых показателей компании КМГ в период с 2014 по 2020 гг. Для выполнения этой задачи составим таблииу 1.

Из вышеприведенной таблицы можно проследить, что за анализируемый временной период 2014-2020 гг. произошли следующие изменения:

- стремительно снизились запасы нефти и газоконденсата $(-18,36$ \%) с 818,3 млн тонн в 2014 году до 668 млн тонн в 2018 году, аналогичная ситуация с объемом запасов природного газа, снижение составило -15,09\%, с 487,6 млрд м ${ }^{3}$ до 414 млрд м ${ }^{3}$ соответственно (примечание: данные по запасам нефти и газа за 2019-2020 гг. представлены в отчетах в общей сумме углеводородов, без разделения на запасы отдельно нефти и газа); 
Таблица 1 - Изменение ключевых показателей АО «НК «КазМунайГаз» за 2014-2020 гг.

\begin{tabular}{|c|c|c|c|c|c|c|c|c|}
\hline \multicolumn{2}{|c|}{ Показатели } & 2014 & 2015 & 2016 & 2017 & 2018 & 2019 & 2020 \\
\hline \multicolumn{2}{|c|}{$\begin{array}{l}\text { Запасы нефти и газоконденсата } \\
\text { (АВС1) (млн тонн) }\end{array}$} & 818,3 & 801,2 & 785,8 & 683 & 668 & & \\
\hline \multicolumn{2}{|c|}{$\begin{array}{l}\text { Запасы природного газа (АВС1) } \\
\text { (млрд м³) }\end{array}$} & 487,6 & 436,7 & 430,7 & 421 & 414 & & \\
\hline \multicolumn{2}{|c|}{$\begin{array}{l}\text { Добыча нефти и газоконденсата } \\
\text { (млн т) }\end{array}$} & 22,49 & 22,67 & 22,64 & 23,3 & 23,6 & 23,6 & 21,7 \\
\hline \multicolumn{2}{|c|}{$\begin{array}{l}\text { Добыча природного и } \\
\text { попутного газа (млрд м³) }\end{array}$} & 7,025 & 7,25 & 7,38 & 7,99 & 8,32 & 8,45 & 8,19 \\
\hline \multirow{2}{*}{$\begin{array}{l}\text { Транспор- } \\
\text { тировка } \\
\text { нефти (млн т) }\end{array}$} & $\begin{array}{l}\text { по магис- } \\
\text { тральным } \\
\text { нефте- } \\
\text { проводам }\end{array}$ & 64,01 & 61,0 & 58,7 & 67,9 & 68 & 67,3 & 64,2 \\
\hline & $\begin{array}{l}\text { морская } \\
\text { транс- } \\
\text { портировка } \\
\text { из порта } \\
\text { Актау }\end{array}$ & 4,6 & 2,0 & 1,6 & 6,95 & 7,07 & 10,7 & 8,99 \\
\hline \multicolumn{2}{|c|}{$\begin{array}{l}\text { Транспортировка природного } \\
\text { газа по магистральным } \\
\text { газопроводам (млрд м³) }\end{array}$} & 105,4 & 102,7 & 88 & 101 & 112 & 103 & 86,6 \\
\hline \multicolumn{2}{|c|}{$\begin{array}{l}\text { Производство основных } \\
\text { нефтепродуктов на трех НПЗ } \\
\text { PK+ НП3 Caspi Bitum PK (млн т) }\end{array}$} & 11,7 & 11,16 & 10,9 & 11,3 & 12,1 & 12,6 & 11,7 \\
\hline \multicolumn{2}{|c|}{$\begin{array}{l}\text { Доход от реализации продукции } \\
\text { и оказания услуг (млрд тенге) }\end{array}$} & 3187 & 1094 & 1857 & 2459 & 6989 & 6859 & 4556 \\
\hline \multicolumn{2}{|c|}{ Чистая прибыль (млрд тенге) } & 207,4 & 398,3 & 306 & 520 & 694 & 1158 & 172 \\
\hline \multicolumn{2}{|c|}{$\begin{array}{l}\text { Свободный денежный поток } \\
\text { (млрд тенге) }\end{array}$} & 12 & -236 & 930 & 207 & 416 & 592 & 88 \\
\hline \multicolumn{2}{|c|}{ Чистый долг (млрд тенге) } & 1484 & 1661 & 1135 & 1344 & 2175 & 2361 & 2598 \\
\hline
\end{tabular}

Примечание: таблица была составлена на основе показателей из разных годовых отчетов компании КМГ.

- по объему добычи нефти и газоконденсата в динамике с 2014 по 2019 года наблюдается увеличение на 4,93\%, но в 2020 году этот показатель продемонстрировал снижение до значения ниже уровня 2014 года, что связано с ограничениями по исполнению соглашения ОПЕК+ и влиянием пандемии коронавируса; 
- по объему добычи природного и попутного газа в целом наблюдался прирост на 20,3\% в 2019 году относительно 2014 года, но, в 2020 году значение данного показателя снизилось на 3,7\% в сравнении со значением в 2019 году;

- 1) с 2014 по 2016 гг. по объему транспортировки нефти по магистральным нефтепроводам наблюдалось постепенное снижение (-8,29\%), с 2016 по 2019 гг. наблюдается увеличение и укрепление объема транспортировки, но в 2020 году, объем транспортировки вновь снижается, практически до уровня 2014 года;

- 2) с 2014 по 2016 гг. по объему морской транспортировки из порта Актау наблюдалось снижение (-65,21\%), после 2016 года наблюдался стремительный рост - в 2019 году прирост относительно значения 2016 года составил $+568,75 \%$. Однако в 2020 году было снижение объема морской транспортировки из порта Актау относительно объема 2019 года на $-15,98 \%$;

- производство основных нефтепродуктов в динамике в целом показывало рост, в сравнении с исходным годом, в 2019 году $+7,69 \%$, однако также наблюдалось отрицательное отклонение в период с 2015 по 2016 гг. по сравнению со значением в 2014 году, отклонение, вероятно, было связано с подготовкой к модернизации и последующей модернизацией на Атырауском и Павлодарском НПЗ. Стоит отметить, что в 2020 году значение все же вернулось на уровень 2014 года;

- особенности динамики цен на нефть, а также увеличение валютного курса в существенной степени повлияли на формирование конечных финансовых результатов компании. Так, доход от реализации продукции и оказания услуг заметно просел в 2015 году относительно 2014 года на -65,67\%, а затем, в период с 2015 по 2019 гг., доход от реализации показывал стабильный рост $(+526,9 \%)$. Но стоит отметить, что в 2020 году доход снова просел на -33,57\% относительно уровня 2019 года;

- чистая прибыль компании в 2014-2015 гг. показала значительный рост с 207,4 млрд тенге до 398,3 млрд тенге, далее в 2016 году чистая прибыль снизилась до 305,8 млрд тенге. После 2016 года наблюдалось стремительное увеличение прибыли до 1158 млрд тенге в 2019 году, пока в 2020 году вновь не снизилась на -85,14\%;

- свободный денежный поток сильно ушел в минус в 2015 году до -236 млрд тенге, затем значительно вырос до 930 млрд тенге в 2016 году, далее заметно снизился в 2017 году до 207 млрд тенге и уже в 2018-2019 гг. пошел в рост до 592 млрд тенге. Но в 2020 году вновь снизился до 88 млрд тенге (-85,13\% относительно 2019 г.);

- чистый долг компании с 2014 года увеличился на 75,07\%.

Сопоставляя проанализированные данные, можно прийти к промежуточному выводу, что фактическая реализация Стратегии КМГ не полным образом соответствует достижению ключевых стратегических целей компании. Вывод подкрепляется следующими обоснованиями, полученными в ходе анализа:

1. Цель по увеличению запасов согласно мерам по реализации Стратегии должна была осуществляться при помощи развития ресурсной базы. Но как мы видим, по объему доказанных запасов нефти и газа на протяжении всего анализируемого периода ежегодно наблюдается спад;

2. Чистый долг компании за весь анализируемый период показывает стабильный рост, что не соответствует основной цели КМГ по укреплению финансовой устойчивости; 
3. За последний анализируемый период 2019-2020 гг. основные финансовые показатели показали значительное снижение, что в свою очередь указывает на то, что компания вероятно не своевременно скорректировала меры реализации на внешние вызовы, что в конечном итоге привело к невыполнению стратегических целей.

Далее, на основе вышеприведенного анализа и информации из отчетов компании проведем SWOT-анализ, в ходе которого обозначим угрозы компании от негативного влияния внешних факторов и слабые стороны, а также сильные стороны и потенциальные возможности для нивелирования негативного влияния на КМГ.

\section{SWOT-анализ}

\begin{tabular}{|c|c|}
\hline Сильные стороны & Слабые стороны \\
\hline $\begin{array}{l}\text {-национальная компания; } \\
\text {-лидирующие позиции по добыче нефти } \\
\text { во внутристрановом рейтинге; } \\
\text {-ускоренный темп цифровизации } \\
\text { производства; } \\
\text {-бренд, имидж; } \\
\text {-человеческий капитал; } \\
\text {-корпоративная культура; } \\
\text {-транспортная инфраструктура; } \\
\text {-инфраструктура для нефтепереработки; } \\
\text {-сагу-финансирование в } \\
\text { геологоразведке. }\end{array}$ & $\begin{array}{l}\text {-зрелые месторождения; } \\
\text {-уменьшение объемов доказанных } \\
\text { запасов нефти и газа; } \\
\text {-высокая долговая нагрузка. }\end{array}$ \\
\hline Возможности & Угрозы \\
\hline $\begin{array}{l}\text {-НИОКР по разведке и добыче; } \\
\text { - увеличение запасов нефти и газа; } \\
\text {-уменьшение расходов и повышение } \\
\text { уровня прозрачности бизнес-процессов } \\
\text { за счет дальнейшего развития } \\
\text { цифровизации; } \\
\text {-диверсификация маршрутов и } \\
\text { направлений сбыта; } \\
\text {-снижение неэффективных и маловажных } \\
\text { административных расходов; } \\
\text {-контроль и снижение операционных } \\
\text { расходов; } \\
\text {-развитие нефтехимии через создание } \\
\text { стратегических партнерств; } \\
\text {-развитие альтернативных источников } \\
\text { энергии через создание стратегических } \\
\text { партнерств. }\end{array}$ & $\begin{array}{l}\text {-низкая цена на нефть; } \\
\text {-обязательное снижение объемов } \\
\text { добычи нефти в рамках сделки ОПЕК+; } \\
\text {-срыв сроков поставок оборудования } \\
\text { и услуг из-за повторных вспышек } \\
\text { коронавируса; } \\
\text { - валютные риски (изменение курса тенге } \\
\text { по отношению к доллару); } \\
\text {-тенденции по декарбонизации и вводу } \\
\text { карбонового налога в странах ЕС; } \\
\text { - риски техногенных аварий; } \\
\text {-правовые риски (изменения в } \\
\text { законодательстве и нпа, иски и споры). }\end{array}$ \\
\hline
\end{tabular}

Примечание: составлена авторами. 
На основе проведенного SWOT-анализа выделим несколько возможных рекомендаций:

1. Для обеспечения прироста объемов доказанных запасов и уменьшения риска потери инвестиций при геологоразведке, применять лучшие практики геологоразведки и привлекать инвесторов для саrry-финансирования. К примеру, ПАО «Газпром нефть» при помощи интеграции новых данных, полученных при опробовании новой технологии «Цифровой анализ керна» (Digital Rock Physics - DRP), существенно уменьшила различие между минимальной и максимальной оценкой геологических и извлекаемых запасов, а также сократить сроки получения результатов без увеличения бюджета $[9$, с. 65,70$]$;

2. Для обеспечения стабильной выручки по реализации газа проводить более гибкую политику сбыта и учитывать необходимость диверсификации маршрутов и направлений сбыта;

3. Расширение доходной базы и освоение новых направлений производства нефтепродуктов и энергии через внедрение проектов по развитию нефтехимии и альтернативных источников энергии с помощью создания стратегических партнерств, применяя лучшие практики в этих направлениях. Создание портфеля активов в сфере возобновляемых источников энергии также может выступить в качестве трансграничного инструмента в рамках перехода компании от традиционных источников энергии к возобновляемым источникам [10, с. 337].

Выводы. Стратегический менеджмент - непрерывный процесс, который требует постоянного мониторинга и оценки эффективности, с возможным внесением своевременной корректировки с учетом изменений во внешней и внутренней среде. Стратегический менеджмент не будет эффективным, если реализация стратегии не будет соответствовать целям, видению и приоритетам, заложенным в основу стратегии компании.

Как итог данного исследования можно сделать вывод о том, что АО «НК «КазМунайГаз» не полным образом осуществлял свои стратегические цели. Так, стоит отметить, что объемы запасов нефти и природного газа в анализируемый период с 2014 по 2020 гг. показывают постоянное снижение, растет чистый долг компании, а свободный денежный поток за весь период демонстрирует нестабильность. Однако у Компании имеются ряд возможностей и сильных сторон для должного выполнения целей и показателей. В этой связи, можно рассмотреть выполнение следующих рекомендаций: 1) по части прироста запасов нефти и газа необходимо применять лучшие практики геологоразведки и продолжать привлекать инвесторов к carry-финансированию затрат на геологоразведочные работы; 2) ввиду грядущего ввода углеродного налога при экспорте в страны ЕС по части увеличения выручки либо угроз недополучения ее, нужно прибегнуть к диверсификации маршрутов и направлений сбыта; 3) в целях расширения доходной базы можно рассмотреть вариант создания стратегических партнерств в проектах нефтегазохимии и ВИЭ. Ввиду усиления тренда развития проектов по выработке альтернативных источников энергии, продвижение работ по данному направлению поможет Компании избежать возможной позиции «аутсайдера» в будущем. 


\section{ЛИТЕРАТУРА}

1 Линник А. Г. Инструменты стратегического планирования в нефртегазовых компаниях// Статистика, учет и аудит. - 2019. - №4(75). - С. 140-145. [Linnik A. G. Instrumenty strategicheskogo planirovaniya v neftegazovykh kompaniyakh. - 2019. - No.4(75), - S. 140-145].

2 Томпсон-мл. А.А., Стрикленд III А. Дж. Стратегический менеджмент: концепции и ситуации для анализа. - М.: Издательский дом Вильямс, 2007. -928 с. [Tompsonml. A.A., Striklend III A. Dzh. Strategicheskiy menedzhment: kontseptsii i situatsii dlya analiza. - Moskva: Publ. Williams, 2007. - S. 928].

3 Чеботарь Ю. М. Корпоративные фринансы и корпоративный контроль: монография. - М.: Автономная некоммерческая организация «Академия менеджмента и бизнес-администрирования», 2016. - 250 с. [Chebotar Yu. M. Korporativnyye finansy i korporativnyy kontrol: monografiya. - Moskva: Avtonomnaya nekommercheskaya organizatsiya «Akademiya menedzhmenta i biznes-administrirovaniya», 2016. - S. 250].

4 Бгашев М. В. Стратегический менеджмент: учебное пособие. - Саратов: Амирит, 2018. - 214 c. [Bgashev M. V. Strategicheskiy menedzhment: uchebnoye posobiye. Saratov: Amirit, 2018 - S. 214].

5 Давлетов И. И., Свечникова Т. М., Черданцев В. П., Черникова С. А. Стратегический менеджмент: учебное пособие. - Пермь: ФГБОУ ВО Пермская ГСХА, 2015. - 96 с. [Davletov I. I., Svechnikova T. M., Cherdantsev V. P., Chernikova S. A. Strategicheskiy menedzhment: uchebnoye posobiye. - Perm: Publ. FGBOU VO Permskaya GSKhA. 2015. - S. 96].

6 Ковени М., Гэнстер Д., Хартлен Б., Кинг Д. Стратегический разрыв. Технологии воплощения корпоративной стратегии в жизнь. - М.: Альпина Паблишер, 2020. 232 c. [Koveni. M., Genster D., Khartlen B., King D. Strategicheskiy razryv. Tekhnologii voploshcheniya korporativnoy strategii v zhizn'. - Moskva: Alpina Pablisher, 2020. - S. 232].

7 Джуха В. М., Штапова И. С., Жуковская Н. П. Стратегический менеджмент: учебное пособие. - Москва: КНОРУС, 2019. - 282 с. [Dzhukha V. M., Shtapova I. S., Zhukovskaya N. P. Strategicheskiy menedzhment: uchebnoye posobiye. - Moskva: KNORUS, 2019. - S. 282].

8 Официальный сайт АО НК «КазМунайГаз» = Oficial'niy sayt AO NK «KazMunajGaz». Access mode: https://www.kmg.kz/rus/kompaniya/obshaya_informaciya/ (дата обращения: 10.10.2020).

9 Морозов В. В., Мельников С. И., Идрисова С. А., Савельев О. Ю., Серебрянская А. У., Билинчук А. В., Загребельный Е. В. Опыт применения технологии «Цифровой анализ керна» на месторождении «Саркала» // Научно-технический журнал «Газпром нефти» «PROнефть. Профессионально о нефти». - 2020. - №3(17). - С. 65-70. [Morozov V. V., Melnikov S. I., Idrisova S. A., Savelyev O. Yu., Serebryanskaya A. U., Bilinchuk A. V., Zagrebelnyy E. V. Opyt primeneniya tekhnologii «Tsifrovoy analiz kerna» na mestorozhdenii «Sarkala» // Nauchno-tekhnicheskiy zhurnal «Gazprom nefti» «PROneft. Professionalno o nefti». -2020. -No.3(17). - S. 65-70].

10 Хашукаев С. Ф. Стратегии российских вертикально-интегрированных нефтяных компаний в условиях неопределенности рынка нефти (на примере ПАО НК «Роснефть») // Инновации и инвестиции. - 2020. - №5. - С. 333-338. [Khashukayev S. F. Strategii rossiyskikh vertikalno-integrirovannykh neftyanykh kompaniy $v$ usloviyakh neopredelennosti rynka nefti (na primere PAO NK «Rosneft»// Innovatsii i investitsii. 2020. - No.5. - S.333-338]. 